\title{
EVALUATION OF CRUDE OIL PROPERTY USING INTELLIGENCE TOOL: FUZZY MODEL APPROACH
}

\author{
Reza Abedini*,1, Morteza Esfandyari ${ }^{2}$, Amir Nezhadmoghadam ${ }^{3}$, Hooman Adib $^{4}$ \\ ${ }^{1}$ Department of Petroleum Engineering, Mahallat Branch, Islamic Azad University, Mahallat, Iran \\ ${ }^{2}$ Member of young researchers club, Islamic Azad University, Quchan branch, Quchan, Iran \\ ${ }^{3}$ Department of Chemical Engineering, Ferdowsi University of Mashhad, Mashhad, Iran \\ ${ }^{4}$ Department of Petroleum Engineering, Petroleum University of Technology, Ahwaz, Iran
}

Received 26 March 2011; accepted 08 August 2011

\begin{abstract}
Viscosity is one of the most important governing parameters of the fluid flow, either in the porous media or in pipelines. So it is important to use an accurate method to calculate the oil viscosity at various operating conditions. In the literature, several empirical correlations have been proposed for predicting undersaturated crude oil viscosity. However these correlations are not able to predict the oil viscosity adequately for a wide range of conditions. In present work, an extensive experimental data of undersaturated oil viscosities from different samples of Iranian oil reservoirs was applied to develop a Fuzzy model to predict and calculate the undersaturated oil viscosity. Validity and accuracy of these models has been confirmed by comparing the obtained results of these correlations and with experimental data for Iranian oil samples. It was observed that there is acceptable agreement between Fuzzy model results with experimental data.
\end{abstract}

Keywords: Viscosity, Correlation, Fuzzy model, undersaturated crude oil

DOI:10.3329/cerb.v15i1.7334

\section{Introduction}

Crude oil viscosity is an important physical property that controls and influences the flow of oil through porous media and pipes. The viscosity, in general, is defined as the internal resistance of the fluid to flow. Oil viscosity is a strong function of many thermodynamic and physical properties such as pressure, temperature, solution gas-oil ratio, bubble point pressure, gas gravity and oil gravity [1].

Numerous correlations have been proposed to calculate the oil viscosity. These correlations are categorized into two types. The first type which refers to black oil type correlations predict viscosities from available field-measured variables include reservoir temperature, oil API gravity, solution gas- oil ratio, saturation pressure and pressure [2-9]. The second type which refers to compositional models derives mostly from the principle of corresponding states and its extensions. In these correlations beside previous properties, other properties such as reservoir fluid composition, pour point temperature, molar mass, normal boiling point, critical temperature and acentric factor of components are used [10-12].

\section{Experimental Data}

In this study, PVT experimental data of five sample oils from Iranian oil reservoirs have been used. These data include oil reservoir temperature, saturation pressure, API gravity and solution gas-oil ratio at reservoir temperature. Reservoir oil viscosities have been measured at various pressures above and below the bubble point pressure for different temperatures. Statistical experimental data are shown in Table 1.

\subsection{Undersaturated oil viscosity correlations}

Under-saturated oil viscosity correlations, which usually use saturated crude oil viscosity and pressure above the bubble point to predict viscosity of undersaturated oil reservoirs. These correlations are Beal [2], Vazquez and Beggs [6], Khan Correlation [13] and Kartoatmodjo and Schmidt [8]. These correlations are shown in Table 2.

\section{Fuzzy Model}

In 1965, Zadeh [14] introduced the concept of a fuzzy subset and studied its properties on the lines parallel to set theory. In this paper we present a fuzzy logic based method to identify the forecasting models. The advantage of prediction methods based on fuzzy set theory is to be able to express the models obtained in the form of fuzzy rules which are very close to human language.

A fuzzy set is characterized by a membership function $\mu_{f}[0,1]$, which associates each element with a

\footnotetext{
*Corresponding author; Email:reza_abedini20@yahoo.com
} 


\begin{tabular}{lllll} 
Table 1: Statistical experimental data of sample oils & \multicolumn{5}{l}{} \\
\hline Oil properties & Oil 1 & Oil 2 & Oil 3 & Oil 4 \\
\hline API & 15.4 & 24.2 & 30.3 & 36.7 \\
Temperature $\left({ }^{\circ}\right.$ F) & $134-272$ & $134-272$ & $134-272$ & $134-272$ \\
Solution gas-oil ratio(SCF/STB) & 647 & 823 & 954 & 1167 \\
Saturation pressure (psia) & $2490-3500$ & $2520-3328$ & $1340-2040$ & $134-272$ \\
Undersaturated viscosity $(\mathrm{cp})$ & $0.394-2.211$ & $0.374-0.726$ & $0.683-18.435$ & $0.316-8.253$ \\
\hline
\end{tabular}

\begin{tabular}{ll} 
Table 2: Summary of undersaturated oil viscosity correlations & \\
\hline Beal, $1946[2]$ & $\mu_{o}=\mu_{o b}+0.001\left(P-P_{b}\right)\left(0.024 \mu_{o b}{ }^{1.6}+0.038 \mu_{o b}{ }^{0.56}\right)$ \\
Vazquez and Beggs, $1980[6]$ & $\begin{array}{l}\mu_{o}=\mu_{o b}\left(P / P_{b}\right)^{m} \\
a=\left[-3.9\left(10^{-5}\right) P\right]-5 \\
m=2.6\left(P^{1.187}\right)\left(10^{a}\right)\end{array}$ \\
Khan, 1987 [13] & $\mu_{o}=\mu_{o b} \exp \left(9.6 \times 10^{-5}\left(P-P_{b}\right)\right)$ \\
Kartoatmodjo and Schmidt, $1994[8]$ & $\mu_{o}=1.00081 \mu_{o b}+0.001127\left(P-P_{b}\right) \times\left(-0.006517 \mu_{o b}{ }^{1.8148}+0.038 \mu_{o b}{ }^{1.59}\right)$
\end{tabular}

grade of membership in the fuzzy set. The main purpose of a fuzzy system is to achieve a set of local inputoutput relationships describing a process.

\subsection{Inference using fuzzy logic}

The most important two types of fuzzy inference method are Mamdani's fuzzy inference method, which is the most commonly seen inference method. This method was introduced by Mamdani and Assilian [15]. Another well-known inference method is the so-called Sugeno or Takagi-Sugeno-Kang method of fuzzy inference process. This method was introduced by Sugeno [16].

Generally, Mamdani fuzzy models are more interpretative than T-S fuzzy models from a human perspective and thus can better explain and describe a modeled system's behaviors. T-S fuzzy systems, on the other hand, are more expressive as they can achieve a high modeling accuracy with a relatively small rulebase. However, the T-S fuzzy rules contain functional consequents that do not lend themselves well to human comprehension. With respect to a single-input- singleoutput system of $y=f(x)$, the structures of a Mamdani and T-S fuzzy rule are described using Equation 1.

Mamdani: $R_{i}$ : if $X$ is $A_{i}$ and $Y$ is $B_{i}$ then $Z$ is $C_{i}, i=1 \ldots n$

T-S: $R_{i}$ : if $X$ is $A_{i}$ and $Y$ is $B_{i}$ then $z_{i}=f_{i}(x 0, y 0), i=1 \ldots n,(x 0, y 0)$ is the input

where $A, B$ and $C$ are linguistic labels represented by fuzzy sets, and $f i(x)$ is a polynomial function of arbitrary order. In this works, the Mamdani fuzzy model is used for prediction and calculating for viscosity of undersaturated crude oil.

Two prediction methods were employed for the study: neural networks and fuzzy logic.

Neural networks are capable of modeling complex nonlinear phenomena. Their main drawback is that they result in a 'black box' model, in other words the model obtained is represented in the form of equations which are not easy to interpret or justify [1, 17].

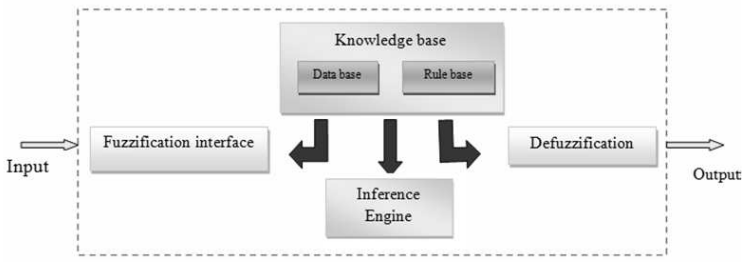

Figure 1: Fuzzy expert system approach

Fuzzy logic also allows one to model complex nonlinear phenomena. The advantage of prediction methods based on fuzzy set theory is to be able to express the models obtained in the form of fuzzy rules very close to human language. This allows us to easily explain and justify the predictions made by the models.

Figure 1 shows a fuzzy inference system. It consists of fuzzifier, defuzzifier and fuzzy inference engine.

\section{Results and Discussion}

\subsection{Validation of undersaturated oil viscosity corre- lations}

The accuracy and ability of each mentioned correlation for predicting undersaturated oil viscosity was checked with experimental data and Figure 2 shows this comparison. This figure confirms the disability of correlations for accurate prediction of oil viscosities.

\subsection{Development of Fuzzy model}

From Figure 3 three inputs to the fuzzy models: pressure bubble, viscosity bubble and pressure bubble. The ranges of these inputs are from [1320 4520], [0.3 14.1] and [1500 6000] respectively. For each input variables Gaussian membership functions (MFs) are requested to use. So we can express these MFs as follows:

$$
f(x, \sigma, c)=e^{\frac{-(x-c)^{2}}{2 \sigma^{2}}}
$$



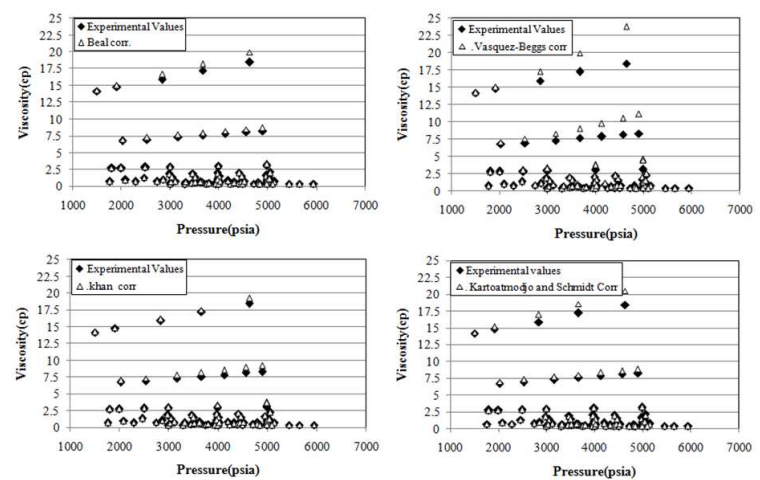

Figure 2: Experimental values compared with calculated values calculated correlations

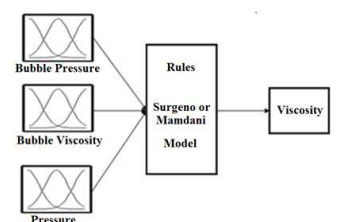

(a)

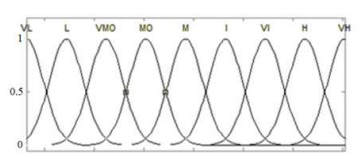

(b)
Figure 3: (a): The built fuzzy inference system,(b): Membership function of input and output variables used in this study (VL: very low, L: low, VMO: very moderate, MO: moderate, M: medium, I: increase, VI: very increase, $\mathrm{H}$ : high, $\mathrm{VH}$ : very high)

The parameters for gaussmf represent the parameters $\sigma$ and $c$ listed in order in the vector. There is one output to the fuzzy model: viscosity.

In practice, fuzzy modeling is applied using local inferences. That means each rule is inferred and the results of the inferences of individual rules are then aggregated. The most common inference methods are: the max-min method, the max-product method and the sum-product method, where the aggregation operator is denoted by either max or sum, and the fuzzy implication operator is denoted by either min or prod.

Especially the max-min calculus of fuzzy relations offers a computationally nice and expressive setting for constraint propagation. Finally, a defuzzification method is needed to obtain a crisp output from the aggregated fuzzy result. Popular defuzzification methods include maximum matching and centroid defuzzification.

Furthermore in this study, the fuzzy reasoning results of outputs are gained by aggregation operation of fuzzy sets of inputs and designed fuzzy rules, where max-min aggregation method and centroid defuzzification method are used.

The fuzzy model rule surfaces showing the relationship between pressure $(P)$, pressure bubble $\left(P_{b}\right)$, viscosity bubble $\left(\mu_{b}\right)$ and viscosity $(\mu)$ are given in Figure 4.

Figure 5 depicts the comparison of experimental values of viscosity with predicted ones by Fuzzy model for undersaturated oil respectively. The result
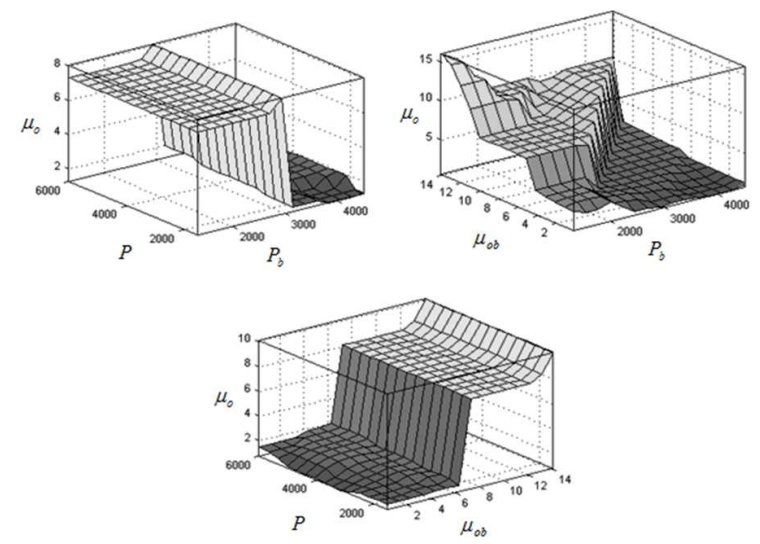

Figure 4: Fuzzy model rules for prediction viscosity

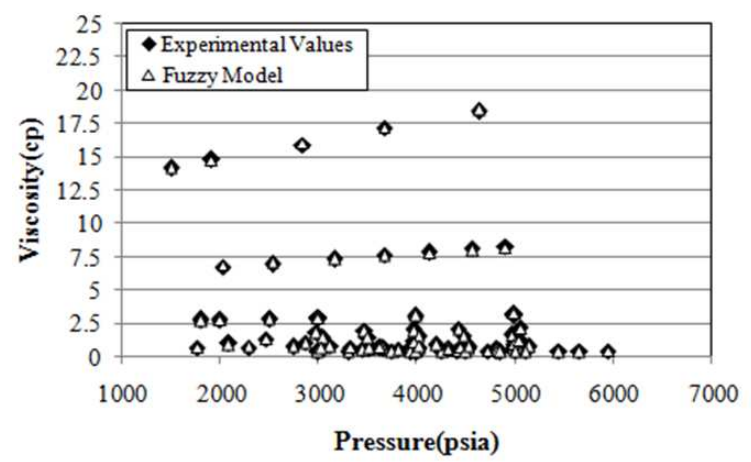

Figure 5: Experimental values compared with calculated values calculated based on the Fuzzy model

from Fuzzy model has an acceptable agreement with experimental values.

\subsection{Accuracy of proposed Fuzzy model}

Here, the accuracy of the proposed models in this work, as well as the correlations previously discussed, is checked. Using the 86 real cases data series of Iranian oils, the results of this work and other ones for estimating the oil viscosity are compared. Figure 6 shows percent relative error distribution for all correlations and models which is defined by Equation 2.

$$
E i=\left(\frac{X_{\text {experimental(i) }}-X_{\text {calculated(i) }}}{X_{\text {experimental(i) }}}\right) \times 100
$$

Table 3 reveals average relative error (ARE), absolute average relative error (AARE) and standard deviation (SD) for undersaturated oil viscosity correlations respectively. ARE, AARE and SD are defined as below [17].

\section{Conclusion}

Generally the most common method for calculating viscosity of crude oils is viscosity correlations. 

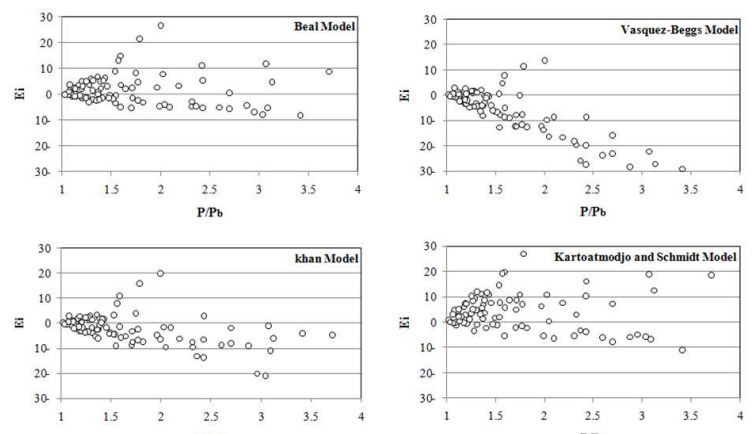

$\mathbf{P P b}$

PPM

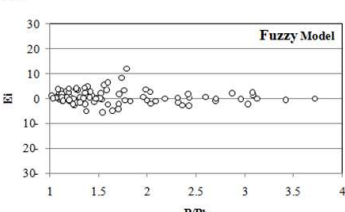

Figure 6: Percent relative error distribution for oil viscosity correlations and Fuzzy model

Table 3: Accuracy of viscosity correlations for prediction undersaturated oil viscosities

\begin{tabular}{lrrr} 
urated oil viscosities & $\begin{array}{r}\mathrm{ARE}^{a} \\
(\%)\end{array}$ & $\begin{array}{r}\mathrm{AARE}^{b} \\
(\%)\end{array}$ & $\begin{array}{r}\mathrm{SD}^{c} \\
(\%)\end{array}$ \\
\hline Correlation & 1.33 & 4.21 & 5.92 \\
Beal, 1946 & 7.83 & 9.12 & 13.83 \\
Vasquez and Beggs, 1980 & -2.44 & 4.64 & 6.48 \\
Khan, 1987 & 4.13 & 6.43 & 9.94 \\
Kartoatmodjo and Schmidt, 1994 & 0.78 & 2.34 & 4.11 \\
Fuzzy Model & & \\
\hline${ }^{a} A R E=\frac{1}{N} \sum_{i=1}^{N}\left(\frac{X_{\text {experimental(i) }}-X_{\text {calculated(i) }}}{X_{\text {experimental(i) }}}\right)$ & \\
${ }^{b} A A R E=\frac{1}{N} \sum_{i=1}^{N}\left(\left|\frac{X_{\text {experimental(i) }}-X_{\text {calculated(i) }}}{X_{\text {experimental(i) }}}\right|\right)$ \\
${ }^{c} S D=\sqrt{\frac{1}{N-1} \sum_{i=1}^{N}\left(\left|\frac{X_{\text {experimental(i) }}-X_{\text {calculated(i) }}}{X_{\text {experimental(i) }}}\right|-A A R E\right)^{2}}$
\end{tabular}

However these correlations fail to predict oil viscosities at wide range of operating conditions such as pressure and temperature. In this work a new Fuzzy model for estimation of undersaturated Iranian oils have been proposed. Input parameters for these models are pressure, saturation pressure and saturation viscosity, which are easily measured in oil fields. The results obtained using Fuzzy model was compared with experimental data. Finally, it was found that in comparison with correlations previously published in the literature, the ability and accuracy of new Fuzzy model for predicting oil viscosities is better.

\section{References}

[1] Abedini R and Abedini A, Development of an Artificial Neural Network Algorithm for the Prediction of Asphaltene Precipitation, Petroleum Science and Technology, 2011. 29(15):pp. 1565-1577. doi:10.1080/10916461003610348

[2] Beal C, The viscosity of air, water, natural gas, crude oil and its associated gases at oil field temperatures and pressures, AIME Transactions, 1946. 165:pp. 94-115

[3] Chew J and Connally CA, Viscosity correlation for undersaturated crude oil, AIME Transactions, 1959. 216:pp. 23-25

[4] Beggs HD and Robinson JR, Estimating the viscosity of crude oil systems, Journal of Petroleum technology, 1975. 27(9):pp. 1140-1141

[5] Glaso O, Generalized pressurevolumetemperature correlation for crude oil system, Journal of Petroleum Technology, 1980. 2:pp. 785-795

[6] Vazquez M and Beggs HD, Correlations for fluid physical property prediction, Journal of Petroleum Technology, 1980. 32(6):pp. 968-970

[7] Labedi R, Improved correlations for predicting the viscosity of light crudes, Journal of Petroleum Science and Engineering, 1992. 8(3):pp. 221-234. doi : 10.1016/0920-4105(92) 90035-Y

[8] Kartoatmodjo T and Schmidt Z, Large data bank improves crude physical property correlations, Oil and Gas Journal, 1994. 92(27):pp. 51-55

[9] Elsharkawy AM and Alikhan AA, Models for predicting the viscosity of Middle East crude oils, Fuel, 1999. 78(8):pp. 891903

[10] Lohrenz J, Bray BC and Clark CR, Calculating viscosities of reservoir fluids from their composition, Journal of Petroleum Technology, 1964. 10:pp. 1170-1176

[11] Little JE and Kennedy HT, A correlation of the viscosity of hydrocarbon systems with pressure, temperature and composition, Society of Petroleum Engineers Journal, 1968. 8(2):pp. 157-162

[12] Ahrabi F, Ashcroft SJ and Shearn RB, High pressure volumetric phase composition and viscosity data for a North Sea crude oil and NGL mixtures, Chemical Engineering Research and Design, 1987. 65:pp. 329-334

[13] Khan SA, Al-Marhoun MA, Duffuaa SO and Abu-Khamsin SA, Viscosity Correlations for Saudi Arabian Crude Oils, in Fifth SPE Middle East Conference, Manama, Bahrain, 1987

[14] Zadeh LA, Fuzzy sets, Information and control, 1965. 8(3):pp. 338-353

[15] Mamdani EH and Assilian S, An experiment in linguistic synthesis with a fuzzy logic controller, International Journal of Man-Machine Studies, 1975. 7(1):pp. 1-13

[16] Takagi T and Sugeno M, Fuzzy identification of systems and its applications to modeling and control, IEEE Transactions on Systems, Man and Cybernetics, 1985. 15(1):pp. 116-132

[17] Abedini R, Zanganeh I and Mohagheghian M, Simulation and Estimation of Vapor-Liquid Equilibrium for Asymmetric Binary Systems (CO2-Alcohols) Using Artificial Neural Network, Journal of Phase Equilibria and Diffusion, 2011. 32(2):pp. 105-114. doi : 10.1007/s11669-011-9851-8 